\title{
Effect Of Mycorrhiza On Plant Growth
}

\author{
${ }^{1}$ Olagunju E.O, ${ }^{1}$ Owolabi K.T and ${ }^{2}$ Alaje D.O \\ ${ }^{1}$ Department of Science Laboratory, Osun State Polytechnic, Iree, Nigeria. \\ ${ }^{2}$ Department of Applied Sciences, Osun State Polytechnic, Iree, Nigeria.
}

\begin{abstract}
Nutrient depletion in soil has become a serious threat to agricultural production, incorporation of factor such as Am Fungi as an alternative amendment in enhancing crop production cannot be underestimated. However, this paper investigates potency of Arbuscular mycorrhirza inoculation on plant growth. The experiment was designed such that 3 planting pots were seeded with sorghum bicolor and Am Fungi, another 3 planting pots were seeded without Am Fungi, in all there were replicate of 4 treatments. Growth parameters such as length of the mid rib, necrosis and dieback were measured. The result obtained showed increases in the length of the mid rib which ranges between $12.70 \mathrm{~cm}-15.40 \mathrm{~cm}$ at week $2,37.80 \mathrm{~cm}-42.70 \mathrm{~cm}$ at week 4 $51.30 \mathrm{~cm}-55.30 \mathrm{~cm}$ at week 6 . and increase in major nutrient absorption with $N(0.94 \%-2.97 \%), P(0.50 \%$ $0.41 \%)$, and $K(5.88 \%-6.07 \%)$ of sorghum bicolor unlike non inoculated sorghum bicolor. Dieback and necrosis of the inoculated sorghum bicolor were less compared to the higher value in non inoculated sorghum bicolor.

Keywords: Arbuscular mycorrhiza, Sorghum bicolor, necrosis, diebark, length of the mid rib
\end{abstract}

\section{Introduction}

Soil degradation and nutrient depletion have increased thus posing a serious threat to agricultural production in the tropical region. The primary limitation of crop production is the deficiency of available nutrient especially phosphorous and water (Nagarathna et al., 2007). The use of inorganic fertilizers by the poor small scale farmers and large scale farmers in some poor developing countries is made difficult by their scarcity. The incorporation of factors that enables plants to withstand nutrient deficiency and toxicity as well as drought stress would therefore be helpful to improve crop production. Inoculation of plant root with Arbuscular Mycorhiza is consider to be effective in improving crop production under nutrient and drought stress conditions (Nagarathia et al., 2007).

Arbuscular mycorrhizae (AM) are symbiotic associations, formed between plants and soil fungi that play an essential role in plant growth, plant protection, and soil quality. The AM fungi expand their filaments in soil and plant roots. This filamentous network promote bi-directional nutrient movement where soil nutrients and water move to the plant and plant photosynthates flow to the fungal network. AM fungi are ubiquitous in the soil and can form symbiosis with most terrestrial plants including major crops, cereals, vegetables, and horticultural plants. In agriculture, several factors, such as host crop dependency to mycorrhiza colonization, tillage system, fertilizer application, and fungi inoculum's potential can affect plant response and plant benefits from mycorrhiza. Due to their obligate symbiotic status, AM fungi need to associate with plant for growth and proliferation.(Hapte, 2000).

Mycorrhiza colonize the cortical tissue of plants roots of most plant species and thus increase the root surface area. Among small proportion of all plants species examined, 95\% of those plant families are predominantly Mycorrhiza.

Mycorrhiza play an important role in plant nutrient and water uptake, particularly on soil with low phosphorous level (Meyer, 2007). Absorptive capacity of immobile nutrient such as N, P, K, Ca, S, Cu , Zn and other micro-elements from the soil cannot be underestimated. Mycorrhiza fungi have been suggested as having a role in mediating the uptake of water at times of drought stress and of metals on contaminated ground. (Farahani et al., 2008).

AIM

To determine the influence of Mycorrhizal on crop production.

\section{OBJECTIVES}

To improve or increase agricultural produce.

To promote sustainable agricultural practices in the emerging globalization trend.

\section{Methodology}

Pot experiment was designed such that sorghum seedlings planted on wood shavings were transplanted into the experimental pots that were filled with good top loamy soil at two weeks. The experiment was designed such that 3 planting pots were seeded with sorghum bicolor and $7 \mathrm{~g}$ of Am fungi, another 3 planting pots were 
seeded without Am fungi. In all there were replicate of four treatments: Inoculated Sorghum(S+), NonInoculated Sorghum(S-), Inoculated Sorghum(S+) and Non-Inoculated Sorghum(S-).

Each treatment was watered regularly with the sorghum growth being monitored and measured at week 2 , week 4 and week 6 after transplanting. The plants were then harvested, blended and the plant biomass tissue was analyzed using (IS0, 2006) technique.

III. Results And Discussion

TABLE 1: Growth analysis of the effect of mycorrhiza on sorghum bicolor.

\begin{tabular}{|c|c|c|c|}
\hline \multicolumn{4}{|c|}{ WEEK 2} \\
\hline Treatments & Length of the Midrib (cm) & Necrosis & Die Back \\
\hline $\mathrm{S}+$ & 12.70 & 2.00 & 18.00 \\
\hline S- & 11.60 & 4.00 & 23.00 \\
\hline $\mathrm{S}+$ & 15.40 & 3.00 & 9.00 \\
\hline S- & 15.20 & 4.00 & 18.00 \\
\hline \multicolumn{4}{|c|}{ WEEK 4} \\
\hline $\mathrm{S}+$ & 37.80 & 5.00 & 7.00 \\
\hline S- & 35.60 & 11.00 & 12.00 \\
\hline $\mathrm{S}+$ & 42.70 & 6.00 & 6.00 \\
\hline S- & 40.00 & 9.00 & 10.00 \\
\hline \multicolumn{4}{|c|}{ WEEK 6} \\
\hline $\mathrm{S}+$ & 55.30 & 5.00 & 5.00 \\
\hline S- & 51.00 & 9.00 & 9.00 \\
\hline $\mathrm{S}+$ & 51.30 & 8.00 & 8.00 \\
\hline S- & 47.00 & 7.00 & 7.00 \\
\hline
\end{tabular}

KEY

S+: Inoculated Sorghum

S-: Non-Inoculated Sorghum

TABLE 2: Analysis of the percentage concentration of nutrient uptake by sorghum bicolor.

\begin{tabular}{|l|l|l|l|l|l|}
\hline Treatments & $\mathbf{N}(\%)$ & $\mathbf{P}(\%)$ & $\mathbf{K}(\%)$ & $\mathbf{C a}(\%)$ & $\mathbf{M g}(\%)$ \\
\hline S+ & 2.97 & 0.50 & 6.07 & 14.95 & 29.82 \\
\hline S- & 1.80 & 0.30 & 3.82 & 13.60 & 23.47 \\
\hline S+ & 0.94 & 0.41 & 5.88 & 60.50 & 29.82 \\
\hline S- & 0.86 & 0.30 & 4.62 & 53.75 & 16.62 \\
\hline
\end{tabular}

\section{Results}

Table 1 indicates the growth analysis of the effect of mycorrhiza on sorghum bicolor at Week 2.

It was observed that the length of the mid rib of the inoculated sorghum bicolor ranges from $12.70 \mathrm{~cm}$ to $15.40 \mathrm{~cm}$ while non-inoculated sorghum bicolor ranges from $11.60 \mathrm{~cm}$ to $15.20 \mathrm{~cm}$. Also the necrosis of the inoculated sorghum bicolor was between 2.00 to 3.00 and non-inoculated sorghum bicolor was 4.00.

The die back of inoculated sorghum bicolor falls between 9.00 to 18.00 and non-inoculated sorghum bicolor falls between 18.00 to 23.00 .

The length of the mid rib of inoculated sorghum bicolor was measured between $37.80 \mathrm{~cm}$ to $42.70 \mathrm{~cm}$ and also non-inoculated sorghum bicolor was between $35.60 \mathrm{~cm}$ to $40.00 \mathrm{~cm}$.

The necrosis of the inoculated sorghum bicolor range was between 5.00 to 6.00, while non inoculated sorghum bicolor was between 9.00 to 11.00 .

The die back of inoculated sorghum bicolor range was between 7.00 to 10.00 while non inoculated sorghum bicolor ranged between 10.00 and 12.00 .

The ranges of the length of mid rib of inoculated sorghum bicolor are between $47.00 \mathrm{~cm}$ to $53.00 \mathrm{~cm}$ while non-inoculated sorghum bicolor ranges are between $47.00 \mathrm{~cm}$ to $51.00 \mathrm{~cm}$.

Necrosis of the inoculated sorghum bicolor was between 5.00 to 8.00 and non-inoculated sorghum bicolor was between 7.00 to 9.00 .

The die back of inoculated sorghum bicolor was between 5.00 to 8.00 and non-inoculated sorghum bicolor was between 7.00 to 9.00 .

Table 2 shows the analysis of the concentration of nutrients uptake by sorghum bicolor.

The percentage concentration of Nitrogen in inoculated sorghum bicolor was between $0.94 \%$ to $2.97 \%$ while concentration of Nitrogen in non-inoculated sorghum bicolor was between $0.86 \%$ to $1.80 \%$. Percentage 
concentration of Phosphorous of inoculated sorghum bicolor was at the range of $0.41 \%$ to $0.50 \%$, while concentration of Phosphorus in non-inoculated sorghum bicolor was $0.30 \%$.

The percentage concentration of Calcium in inoculated sorghum bicolor was between $14.95 \%$ to $60.50 \%$ and concentration of Calcium in non-inoculated sorghum bicolor was between $13.60 \%$ to $53.75 \%$.

$\mathrm{Mg}$ concentration was $29.82 \%$ in the inoculated soil and was valued between $23.47 \%$ to $16.62 \%$ in non-inoculated soil.

\section{Discussion}

Increase in the length of the mid rib of the inoculated sorghum bicolor could be attributed to the increase in the surface area of the sorghum bicolor roots that enhances nutrients absorption, as reported by (Selose et al., 2006).

The negative growth measurement - necrosis and die back of the inoculated sorghum bicolor was lower compared to non-inoculated sorghum bicolor. This is as a result of the inoculum that enhances diseases resistance on the inoculated sorghum bicolor (David et al., 2000).

Higher nutrient absorption of inoculated sorghum bicolor compared to non-inoculated sorghum bicolor was as a result of the symbiotic relationship between plant root and soil fungus, thus nutrient obtained by inoculated sorghum bicolor was enhanced especially phosphorous which usually lower or lacking in non mediated soil (Hogan, 2011).

Arbuscular mycorrhiza affect plant and soil microbial activity by stimulating the production of root exudates, phytoalexins and phenolic compounds which increases activity of plant defence genes especially chitinases, glucanases and flavonoid biosynthesis (Al-karaki et al, 2004).

However, this has been observed in the inoculum treatments, thus Mycorrhiza promotes drought and disease resistance.

\section{Conclusion And Recomendation}

Data obtained from this research work showed potency of mycorrhiza inoculum on plant growth and crop production due to its nutrient absorptive capacity and diseases resistance. However, Am mycorrhiza could be used in cultivating crop in order to maximize agricultural produce as well as sustainable agriculture.

\section{References}

[1]. Al-Karaki G.N, McMichael B., and Zak J., (2004): Field response of wheat to Arbuscular mycorrhizal fungi and drought stress. Mycorrhiza 14(4), $263-269$.

[2]. Abbott L.K., \& Robson AD., 1984: The effect of VA mycorrhizae on plant growth. In C.L.L. Powell \& D.J. Bagyarj (eds.). VA Mycorrhizae. CRC press, Boca Raton, FL. 113-127.

[3]. Auge R.M., (2001): Water relation drought and vesicular Arbuscular Mycorrhizal simbiosis. Mycorrhiza 11, 3-42.

[4]. Bagayoko M., George E., Romheld V. \& Bubrkert A., (2000): Effect of mycorrhizal and phosphorous on growth, and nutrient uptake of millet, cowpea and sorghum on Western African soil. J. of Agric. Sci. Cambridge 135, 399-4-7.

[5]. Davies Research Page' Aggocjprtoclture. Tamu. Edu. http/aggiehoticulture. Tamu.Edu/faculty/davies/research/mycorrhzae. Html. retrieved 2010 - $09-30$.

[6]. Farahani H.A; Labaschi M.H and Hamis A. (2008): effects of abuscular mycorrhizal fungi, phosphorous and water stress on quantity and quality characteristic of coriciader. Adv. In National and Appl. Sci. 2(2), $55-59$.

[7]. Habte M, and Silva J.A. (2000): Mycorrhizal fungi and plant nutrition management in Hawail's soils, approaches for Tropical and Subtropical Agriculture, College of manoa.

[8]. Joubert S. and Acrher E. (2000): The influence of Mycorrhiza on vines wynboer. A technical guide for vine producer 130,86 -88.

[9]. Kaliqa and Sanders F.E., (2000): Effect of vericular-arbscular mycorrhza inoculation on the yield and phosphorous uptake of field grown barley. Soil Biol and biochem. 32, $1691-1969$.

[10]. Meyer A., (2007): The Mycorrhizal fungus, A life long partner of the grape vine. Wynboer, a technical guide for wine producer 76,72-74.

[11]. Micheal Hogan, (2011): Phosphate encyclopedia of health. Topic ed. Andy Jorgensen. Ed. In-chief C.J. Cleveland. National Council for Science and the Environment, Washington DC.

[12]. Nagarathna, T.K, Prasad, T.G. Bagyaraj, D.J and Shadakshari, Y.G., (2007): Effect of arbuscular mycorrhizal and phosphorous level on growth and water use efficiency in sunflower at different soil moisture status. J. of Agric. Tech. 3 (2), $221-229$.

[13]. Selosse M.A., Richard F, Simard S.W., (2006): Mycorrhizal networks desliaisons dangereuses? 'trends Ecol Evol.21(11): 621 628 doi: 1016/j.tree.2006.07.003 PMD 16843567.

[14]. Seymour N., (2009): Mycorrhiza and their influence on P Nutrition Queensland department of primary industries and fisheries.

[15]. Sylvia D.M., Fuhrmann J.J., Hartel P.G. and Zuberer, D.A., (2004): Overview of mycorrhizal symbiosis. Principles and application of soil microbiology, $2^{\text {nd }}$ edn.

[16]. Turk M.A., Assaf T.A., Hameed K.M., \& Al. Tawaha. A.M., 2006: Significant of mycorrhiza worlds of Agric. Sci. 2 (1), 16 -20. 